\title{
Water vapor and oxygen-barrier performance of corn-zein coated polypropylene films
}

\author{
Funda Tihminlioglu ${ }^{\mathrm{a}, *}$, İsa Doğan Atik ${ }^{\mathrm{a}}$, Banu Özen ${ }^{\mathrm{b}}$ \\ a Department of Chemical Engineering, Faculty of Engineering, Izmir Institute of Technology, Gülbahçe Urla 35430, Izmir, Turkey \\ ${ }^{\mathrm{b}}$ Department of Food Engineering, Faculty of Engineering, İzmir Institute of Technology, Gülbahçe Urla 35430, Izmir, Turkey
}

\section{A R T I C L E I N F O}

\section{Article history:}

Received 6 October 2008

Received in revised form 31 July 2009

Accepted 8 August 2009

Available online 18 August 2009

\section{Keywords:}

Corn-zein

Polypropylene

Food packaging

Barrier properties

Oxygen permeability

Water vapor permeability

\begin{abstract}
A B S T R A C T
A novel corn-zein coating structure on polypropylene (PP) films was developed to examine its feasibility as an alternative water vapor and oxygen-barrier for flexible packaging industry. The barrier properties of the resulting films were evaluated as affected by coating formulation (solvent, corn-zein, plasticizer concentration and plasticizer type). Corn-zein with different amounts ( $5 \%$ and $15 \%$ ) was dissolved in $70 \%$ and $95 \%$ aqueous ethanol solution at $50{ }^{\circ} \mathrm{C}$, respectively. Solutions of corn-zein plasticized by polyethylene glycol (PEG) and glycerol (GLY) with various levels (20\% and 50\%) were applied on corona-dischargedtreated PP by using solvent-casting method. The significant improvements in water vapor and oxygenbarrier properties of uncoated PP films were obtained with corn-zein coating. Water vapor permeability (WVP) of the coated films decreased significantly with increasing corn-zein concentration. The application of plasticized corn-zein coating on PP films showed nearly more than three order of reduction in oxygen permeability (OP). The high water vapor and oxygen-barriers were obtained for films coated with coating formulation consisting of higher amounts of corn-zein plasticized by GLY. The statistical analysis defined the key parameters of coating formulation that had major effect on the final properties of coated PP films as corn-zein, plasticizer concentration, and plasticizer type.
\end{abstract}

(c) 2009 Elsevier Ltd. All rights reserved.

\section{Introduction}

The purpose of food packaging is to preserve the quality of the food from its manufacture to consumer use. The most common quality losses are associated with water vapor and oxygen transfer. They can be blocked only by using barrier coatings on packaging materials (US Congress, Office of Technology Assessment, 1993). The conventional barrier coatings typically consist of expensive and synthetic polymers such as ethylene vinyl alcohol (EVOH) and polyvinylidene chloride (PVDC). Although these are excellent synthetic coatings, their disadvantage is related to difficulty entailed in their recycling due to not easy separation of coating from coated surface. It is well known that only the recycling of single component thermoplastic films is generally feasible, and the coated films containing layers of different synthetic polymers may not be recycled. Furthermore, the growing reliance on these synthetic coated packaging films has risen on number of environmental concerns (US Congress, Office of Technology Assessment, 1993; Tharanathan, 2003). The increased consumption of these laminated packaging films has resulted in increased environmental waste. Therefore, food industry is considering alternative packag-

\footnotetext{
* Corresponding author. Fax: +90 2327506645.

E-mail address: fundatihminlioglu@iyte.edu.tr (F. Tihminlioglu).
}

ing materials for coatings in terms of recyclability, reutilization, easy separation from surface, and ecological friendliness. Today, there is an increasing interest in the development of biodegradable polymers as barrier coatings for packaging industry (Chandra and Rustgi, 1998; Cutter, 2006; Reddy et al. 2003). The most important advantage of this type of coatings is an easy separation from the surface by chemical or enzymatic processes, and this provides a higher possibility for recycling. These biodegradable coating materials include polysaccharides (i.e. starch, cellulose, chitosan/chitin), proteins (whey protein, corn-zein, wheat gluten, soy protein), or lipids (animal, plant-derived, etc.) (Chandra and Rustgi, 1998). Many research studies of biodegradable coating based on polysaccharides, whey proteins and lipids have been well reviewed (Cuq et al., 1998; Hong and Krochta, 2004, 2006; Hong et al., 2005; Miller and Krochta, 1997; Debeaufort et al., 1998). The barrier properties especially to water vapor of polysaccharide-based coatings are lower compared to protein-based coatings due to specific structures of proteins which confer a wider range of potential functional properties, especially high intermolecular binding potential. High molecular weight proteins are generally insoluble in water and are thus suitable to form water vapor resistant coatings (Cuq et al., 1998).

Particularly among proteins, the extremely good barrier properties of corn-zein proteins make them potentially useful as a barrier 
coating material for food packaging (Lai and Padua, 1997; Lawton, 2004). Zein is the alcohol-soluble protein found in corn endosperm, and it is the byproduct of the corn wet milling industry. Zein is a relatively hydrophobic and thermoplastic material; this hydrophobicity is related to its high content of non-polar amino acids (Shukla and Cheryan, 2001). The packaging films made from an alcoholsoluble protein like ${ }^{* *}$ corn-zein, have relatively high barrier properties compared to other proteins. However, studies are limited with only usage of corn-zein as stand-alone films (Lai and Padua, 1997; Lawton, 2004; Shukla and Cheryan, 2001; Bertuzzi et al., 2007; Wang and Padua, 2006). Corn-zein may also be taken part in coating of conventional packaging plastics. Polypropylene (PP) has been widely used in diverse packaging applications due to abundant supply, low cost and processability. PP is usually coated with previously mentioned synthetic polymers including EVOH, or PVDC to obtain higher barrier properties in which the resulting films are quite expensive and non-recyclable. Therefore, replacing these synthetic barrier layers with corn-zein protein coatings provide a new path for use of corn-zein and improve recyclability of PP.

This study is aimed to develop a novel film structure of plasticized corn-zein coatings on PP films for food packaging applications, and to examine in detail water vapor permeability properties of the resulting coated film as affected by coating formulation (solvent, corn-zein and plasticizer concentrations and also plasticizer type).

\section{Experimental}

\subsection{Materials}

Commercial corona-discharged-treated polypropylene cast film of $40 \mu \mathrm{m}$ thickness (C11/40) obtained from the Polinas Company (Manisa, Turkey). Corn-zein used in this work was obtained from Sigma-Aldrich. Ethanol (99.5\%) used as a solvent was supplied from Panreac and it was diluted with distilled water to prepare two different solvent concentrations which are $70 \%$ and $95 \%$. Polyethyleneglycol (PEG) and glycerol (GLY) used as plasticizer to overcome film brittleness was obtained from Merck and Sigma, respectively.

\subsection{Preparation of corn-zein coated PP films}

Corn-zein film solutions were prepared by dissolving zein to different concentrations between $5 \%$ and $15 \%(\mathrm{w} / \mathrm{v})$ in aqueous ethanol solution by stirring for $2 \mathrm{~h}$ at $50{ }^{\circ} \mathrm{C}$. Concentration of ethanol also ranged between $70 \%$ and $95 \%(v / v)$. Solutions of corn-zein were plasticized by both polyethylene glycol (PEG) and glycerol (GLY) at various levels ( $20 \%$ and $50 \%$ based on corn-zein weight). Following addition of plasticizers, stirring was continued for a further $2 \mathrm{~h}$. Then, film solutions were cast by using conventional solvent-casting technique on corona-discharge-treated PP. Finally, corn-zein coated PP films were dried at $50^{\circ} \mathrm{C}$ for $2 \mathrm{~h}$ under vacuum of 200 mbar. Then, the temperature of the vacuum oven was increased to $120^{\circ} \mathrm{C}$ to allow further evaporation of solvent. The thickness of the corn-zein coating on PP film was in the range of 3-4 $\mu \mathrm{m}$.

\subsection{Water vapor permeability}

Water vapor permeability (WVP) was determined gravimetrically according to the ASTM E96 standard method. The method is performed by sealing a film to the open mouth of a test dish containing silica gel and placing the assembly into a controlled environmental chamber at $60 \%$ relative humidity $(\mathrm{RH})$ and $25^{\circ} \mathrm{C}$. This allows the conditions with low humidity on one side of the film and high humidity on the other side. The water vapor absorbed by silica gel was detected by weighing the silica containing dish periodically until a stationary state was reached. For each measurement, at least three replications were made. WVP was calculated as;

$\mathrm{WVP}=\frac{\Delta W}{A \times \Delta t} \times \frac{x}{\Delta p}$

where $\Delta W$ is the weight gain by silica gel $(\mathrm{g}), x$ is the film thickness $(\mathrm{mm}), A$ is the transfer area of the exposed film surface $\left(\mathrm{m}^{2}\right), \Delta t$ and $\Delta p$ are test time (h) and partial pressure difference in $\mathrm{kPa}$, respectively.

\subsection{Oxygen permeability}

The oxygen permeability (OP) of coated PP films was measured using oxygen permeation instrument, OX-TRAN 2 (MOCON, Minneapolis, MN, USA) according to the ASTM D3985 standard. Oxygen permeabilities of coated films were determined at constant temperature $\left(23^{\circ} \mathrm{C}\right)$ and relative humidity $(0 \% \mathrm{RH})$ conditions. The coated film was placed between two sides of test chamber. One side was exposed to carrier gas containing $98 \% \mathrm{~N}_{2}$ and $2 \% \mathrm{H}_{2}$ while the other side was exposed to test gas of $5 \% \mathrm{O}_{2}$ and $95 \%$ $\mathrm{N}_{2}$. The sensor monitoring the exit port of the carrier gas side measured the amount of oxygen present. The measurement was completed when the concentration of oxygen in the exit of carrier gas was constant and then OP was calculated by dividing exit concentration with transfer film area and time required to reach for stationary state. Furthermore, since overall permeability of multilayer structure is calculated, permeability of each layer could also be calculated by using the following equation known as two layer-model;

$\frac{L}{P}=\sum_{i=1}^{n} \frac{L_{i}}{P_{i}}$

where $n$ is the number of layers, $L$ and $P$ are the thickness and permeability of the multilayer film, $L_{i}$ and $P_{i}$ is the thickness and permeability of each layer. The permeability of corn-zein coatings was calculated with the knowledge of thickness and permeability data.

\subsection{Contact angle analysis}

The surface hydrophobicity or wettability of the films was evaluated by contact angle measurements carried out with water using a goniometer (Kruss G10, Germany). To perform the measurements, a syringe was filled with $5 \mathrm{ml}$ of water, and a drop was placed on top of the film surface that was glued on a well-leveled plastic platform. The angle between the baseline of the drop and the tangent at the drop boundary was measured. For each film type, at least five measurements on different positions of film surface were made and the average was taken.

\subsection{Design of experiments}

Statistical analysis based on full factorial design was performed to examine the influence of the three variables on the final properties of corn-zein coated PP films. The model included factors of two replications at center point, for corn-zein concentration (5 wt.\% and $15 \mathrm{wt} . \%$ ), ethanol concentration (70 wt.\% and $95 \mathrm{wt} . \%$ ) and plasticizer concentration (20\% and 50\%) for each plasticizer containing films; GLY and PEG. These variables were examined at three levels: upper, midpoint and lower limits. Testing of all three factors (ethanol, corn-zein and plasticizer concentrations) simulta- 
neously would involve factorial design with eleven experiments for a single plasticizer containing different coating solution (Table 1) determined by statistical analysis system, MODDE version 7.0. Responses measured were water vapor permeability and contact angle.

\section{Results and discussions}

It is well known that water vapor and oxygen-barrier properties of packaging materials are important factors determining the shelf-life of food products. Transport properties of coated packaging materials are often influenced by coating composition. Since barrier properties of packaging material are responsible for product quality deterioration and shelf-life reduction, the detailed understanding of the characteristics of coated films is great practical and commercial importance. Therefore, design and optimization of the coating composition become more important for food packaging materials. In this study, the plasticized corn-zein coatings with polyethylene glycol (PEG) and glycerol (GLY) on PP films were prepared to evaluate the water vapor and oxygen permeability properties of coated films as affected by solvent, corn-zein, and plasticizer concentration, and also by plasticizer type.

Statistical analysis of data obtained from full factorial design was performed to examine the relationship among these different factors. Factors were examined at two levels, typically one of the upper and the other one is lower limit. Central points were also included in the design. Testing of all four factors (ethanol, corn-zein, and plasticizer concentration, and also plasticizer type) simultaneously would involve factorial design with eleven experiments determined by statistical analysis system, MODDE version 7.0.

\subsection{Water vapor permeability of coated films}

Water vapor permeability values $\left(\mathrm{g} \mathrm{mm} / \mathrm{kPa} \operatorname{min~} \mathrm{m}^{2}\right.$ ) of cornzein coated PP films were tabulated in Table 1. According to statistical analysis of the results, it was determined that solvent, corn and plasticizer concentrations were all significant factors affecting the water vapor barrier properties of the developed multilayer films. As seen from Table 1, significant improvement in water vapor barrier of PP base film was obtained. The improvement in WVP was observed for all coating formulations compared to the uncoated PP film having WVP value of $7.1 \times 10^{-4} \mathrm{~g} \mathrm{~mm} / \mathrm{kPa}$ min $\mathrm{m}^{2}$. According to statistical analysis of WVP permeability data, models developed were significant at $p<0.05$. Coefficients of the parameters and their significance levels are listed in Table 2.

\subsubsection{The effect of plasticizer type and concentration on WVP}

Plasticizers were added to corn-zein coating solutions to reduce brittleness. They work as spacers between protein chains decreasing intermolecular forces and thus increase the flexibility and the extensibility of corn-zein films.

Statistical analysis revealed that addition of plasticizers increased permeability of corn-zein coated PP films to water vapor presumably due to an increase in free volume between protein chains. Plasticizers may have increased the polymer free volume that allowed the segments of polymeric chains to increase their mobility, and the increase in the effective diffusion coefficient of water vapor in the films was also resulted by this increment of the mobility of protein chains. It was observed that the transfer rate of water vapor is closely related to the mobility of the polymer chains and especially free volume of chain segments (Duda et al., 1982; Kumar and Gupta, 1998). The higher segment mobility resulted in higher water vapor permeability of coated PP films.

The higher WVP of corn-zein coated PP films plasticized by PEG as compared to GLY plasticized films may be related to the hydration of the plasticizers since water is more closely associated with PEG compared to GLY. It is known that the PEG system is more effective in attracting water molecules to the film surface. Furthermore, formation of less dense structure in corn-zein coating solution by PEG initiated water vapor permeability and more hydrophilic nature of PEG compared to GLY may also cause an increase in WVP. In general, it can be concluded that high ratio of plasticizer to corn-zein amount resulted in a rise in WVP of coated

Table 1

The WVP of corn-zein coated PP films prepared according to experimental design.

\begin{tabular}{|c|c|c|c|c|c|}
\hline $\begin{array}{l}\text { Coated } \\
\text { film no. }\end{array}$ & $\begin{array}{l}\text { Ethanol } \\
\text { concentration, \% } \\
(\mathrm{v} / \mathrm{v})\end{array}$ & $\begin{array}{l}\text { Corn-zein } \\
\text { concentration, \% } \\
(\mathrm{w} / \mathrm{v})\end{array}$ & $\begin{array}{l}\text { Plasticizer } \\
\text { concentration, \% } \\
(\mathrm{w} / \mathrm{w})\end{array}$ & $\begin{array}{l}\text { GLY plasticization water vapor permeability } \\
\times 10^{4}\left(\mathrm{~g} \mathrm{~mm} / \mathrm{kPa} \mathrm{min} \mathrm{m}^{2}\right)\end{array}$ & $\begin{array}{l}\text { PEG plasticization water vapor permeability } \\
\times 10^{4}\left(\mathrm{~g} \mathrm{~mm} / \mathrm{kPa} \mathrm{min} \mathrm{m}^{2}\right)\end{array}$ \\
\hline 1 & 70 & 5 & 20 & $0.95 \pm 0.14$ & $1.51 \pm 0.41$ \\
\hline 2 & 95 & 5 & 20 & $0.44 \pm 0.02$ & $0.92 \pm 0.05$ \\
\hline 3 & 70 & 15 & 20 & $0.93 \pm 0.11$ & $1.62 \pm 0.39$ \\
\hline 4 & 95 & 15 & 20 & $0.23 \pm 0.03$ & $4.55 \pm 048$ \\
\hline 5 & 70 & 5 & 50 & $2.15 \pm 0.53$ & $6.60 \pm 3.20$ \\
\hline 6 & 95 & 5 & 50 & $3.89 \pm 1.06$ & $4.08 \pm 0.39$ \\
\hline 7 & 70 & 15 & 50 & $2.32 \pm 0.38$ & $1.50 \pm 0.36$ \\
\hline 8 & 95 & 15 & 50 & $0.12 \pm 0.05$ & $3.51 \pm 0.67$ \\
\hline 9 & 82.5 & 10 & 35 & $0.31 \pm 0.04$ & $3.04 \pm 0.82$ \\
\hline 10 & 82.5 & 10 & 35 & $0.29 \pm 0.04$ & $2.70 \pm 1.38$ \\
\hline 11 & 82.5 & 10 & 35 & $0.31 \pm 0.06$ & $0.60 \pm 0.15$ \\
\hline
\end{tabular}

Table 2

Statistical analysis results of water vapor permeability of corn-zein coated PP films.

\begin{tabular}{|c|c|c|c|c|}
\hline \multirow{2}{*}{$\begin{array}{l}\text { WVP } \\
\text { Factors }\end{array}$} & \multicolumn{2}{|l|}{ PEG } & \multicolumn{2}{|l|}{ GLY } \\
\hline & Coeff. SC & $P$ & Coeff. SC & $P$ \\
\hline Solvent concentration & $5.502 \mathrm{e}-005$ & $7.781 \mathrm{e}-4$ & -0.000121 & $3.625 e-005$ \\
\hline Corn concentration & $8.753 e-005$ & $2.801 \mathrm{e}-006$ & -0.000173 & $1.564 \mathrm{e}-007$ \\
\hline Plasticizer concentration & $4.377 \mathrm{e}-005$ & 0.005311 & 0.000126 & $2.161 \mathrm{e}-005$ \\
\hline Solvent-corn interaction & $1.114 \mathrm{e}-005$ & 0.441355 & $5.134 \mathrm{e}-005$ & 0.04526 \\
\hline Solvent-plasticizer interaction & $-1.294 \mathrm{e}-005$ & 0.372109 & $-2.065 e-005$ & 0.40518 \\
\hline Corn-plasticizer interaction & $-4.905 e-005$ & 0.002180 & $-9.158 \mathrm{e}-005$ & 0.000889 \\
\hline
\end{tabular}


PP films while films with zein coating having low plasticizer content have high barrier to water vapor.

Several authors studied the influence of the plasticizer content on barrier properties of zein films, and they showed that there is an increase in WVP of films with an increase in plasticizer content (Lai and Padua, 1997; Parris and Coffin, 1997; Ghanbarzadeh et al., 2006b; Rakotonirainy and Padua, 2001). The results of these studies agree with those reported in this study. Parris and Coffin (1997) studied the effect of various plasticizers on the WVP of the freestanding zein films. Water vapor barrier properties were the best for unplasticized zein films, and incorporation of plasticizers, PEG and GLY, into the zein films resulted in an almost doubling of WVP values. The increase in WVP was more pronounced for films plasticized with PEG which is similar with our findings (Parris and Coffin, 1997). Lawton (2004) studied the relationship between plasticizer type and water sorption of zein films and it was reported that the amount of absorbed water by films depend on the plasticizers used in the film in the order of GLY > PEG. It was also found that plasticizing efficiency increased with the increasing molecular weight of the plasticizer. Thus, PEG plasticized films had higher plasticizing efficiency than GLY plasticized films. Therefore, these results in literature confirm our permeability results of the films plasticized with PEG having higher values than GLY plasticized films.

\subsubsection{The effect of solvent and corn-zein concentration}

Since corn-zein has hydrophobic character due to its high content of non-polar amino acids, corn-zein films were expected to have variable behavior against water vapor depending on its concentration in the film. In addition, ethanol concentration affects the solubility of corn-zein and this resulted in different permeability properties of coated films.

Since the amount of corn-zein present in the coating formulations affects the hydrophobicity of coated PP films, the WVP of films was influenced by corn-zein concentration. The films coated with solutions containing higher amount of zein created the more hydrophobic nature than the coated PP films containing low cornzein in the coating solutions, thus the improvement in the water barrier properties was observed for high concentrations of zein.

According to statistical analysis (Table 2), solvent (ethanol) and corn concentration have significant effect on WVP of PEG and GLY plasticized films. When PEG was used as the plasticizer, increase in solvent and corn concentration resulted in a rise of WVP. However, in case of GLY plasticized films, increased solvent and corn concentration have a decreasing effect on WVP. For GLY as the plasticizer, solvent and corn interaction was also a significant factor at $p<0.05$.

\subsection{Oxygen-barrier properties of coated films}

The good oxygen-barrier properties of corn-zein coated PP films are critical for achieving a long shelf-life for the packaged food products as water barrier properties. The oxygen transmission rates (OTR) of some of the corn-zein coated PP films measured at $23^{\circ} \mathrm{C}$ and $0 \% \mathrm{RH}$ were given in Table 3 as a function of plasticizer type and its concentration.

The OTR values of PP films was significantly decreased upon with corn-zein coating. The application of plasticized corn-zein coating on PP films showed nearly more than two or three order of reduction in OTR of PP films when compared to without coating (in where OTR of PP film was determined as $2000 \mathrm{cc} / \mathrm{m}^{2} \times$ day).

It is found that oxygen transmission value increased with the plasticizer content. The increase in $\mathrm{O}_{2}$ permeability with plasticizer content is associated with the hydrophilic nature of plasticizers used. The further break down of hydrogen bonds created additional sites for the dissolution of oxygen and increased the mobility
Table 3

The effects of plasticizer type and concentration on the OTR of coated PP films ${ }^{\mathrm{a}}$.

\begin{tabular}{lll}
\hline $\begin{array}{l}\text { Plasticizer } \\
\text { type }\end{array}$ & $\begin{array}{l}\text { Plasticizer concentration, \% }(\mathrm{w} / \mathrm{w}) \\
\text { (based on corn-zein content) }\end{array}$ & $\begin{array}{l}\text { Oxygen transmission } \\
\text { rate }\left(\mathrm{cc} / \mathrm{m}^{2} \times \text { day) }\right.\end{array}$ \\
\hline \multicolumn{2}{l}{ Uncoated PP films } & 2000 \\
PEG & 20 & 811 \\
PEG & 50 & 858 \\
GLY & 20 & 609 \\
GLY & 50 & 488 \\
\hline
\end{tabular}

a Where ethanol and corn-zein concentrations are constant at $95 \%$ and $5 \%$, respectively.

of the $\mathrm{O}_{2}$ molecules within the coating layer. The higher mobility of the corn-zein chains resulted in easy $\mathrm{O}_{2}$ diffusion through the film. High humidity may also cause swelling of the film and allows faster diffusion of the gases.

Furthermore, type of plasticizer used also influenced OTR of the corn-zein coating on PP films. Corn-zein coatings plasticized with PEG on PP films had higher OTR values compared to GLY plasticized films. The increase in corn-zein concentration of coating solution from $5 \%$ to $15 \%(\mathrm{w} / \mathrm{v})$ resulted in higher $\mathrm{O}_{2}$-barrier property of coated PP films. The OTR of PP coated films with solution containing $15 \%(\mathrm{w} / \mathrm{v}$ ) corn-zein plasticized with $20 \%$ PEG was measured to investigate the effect of corn-zein concentration on OTR. The OTR of this coated PP film was determined as $466 \mathrm{cc} / \mathrm{m}^{2} \times$ day which was lower than PP film coated with solution containing $5 \%$ (w/v) corn-zein plasticized with 20\% PEG shown in Table 3 as $811 \mathrm{cc} / \mathrm{m}^{2} \times$ day. This improvement was caused by the excellent oxygen-barrier properties of free-standing zein films, thus higher amount of zein present in coating formulation resulted in lower $\mathrm{O}_{2}$ permeability of coated PP film.

The high oxygen-barrier property of free-standing zein films is well known from several reviews published in literature (Cuq et al., 1998; Rakotonirainy and Padua, 2001; Hsu et al., 2005). It was reported that oxygen permeability values of zein films are lower than those of common synthetic plastic films such as low density polyethylene (LDPE), high-density polyethylene (HDPE), PP, polystyrene (PS), and poly (vinyl chloride) (PVC). Furthermore, Shin and coworkers (2002) obtained excellent oxygen-barrier of corn-zein coated LDPE films in agreement with our results. They showed that LDPE films coated with zein reduced oxygen permeability compared to uncoated LDPE. Bilayer films including cornzein coating showed nearly 10 times lower oxygen permeability (Shin et al., 2002).

For using two layer-model, the $\mathrm{O}_{2}$ permeability (OP) of cornzein coating can be calculated from Eq. (2). The estimated OP values of corn-zein coating plasticized using PEG and GLY according to experimental design were listed in Table 4.

In Table 5, the comparison of OP values corn-zein coating determined in this study were compared with the common coating materials used in the industry. From the results, it can be said that the corn-zein coatings show potential to use as an oxygen-barrier packaging material.

Table 4

The oxygen permeability of corn-zein coatings ${ }^{\mathrm{a}}$

\begin{tabular}{lll}
\hline $\begin{array}{l}\text { Plasticizer type/ } \\
\text { concentration }\end{array}$ & $\begin{array}{l}\text { Ethanol \% }(\mathrm{v} / \mathrm{v}) / \text { corn-zein } \\
(\mathrm{w} / \mathrm{v}) \text { concentration }\end{array}$ & $\begin{array}{l}\text { Oxygen permeability } \\
\left(\mathrm{cc} / \mathrm{m}^{2} \times \text { day }\right)\end{array}$ \\
\hline PEG/20 & $95 / 5$ & 90.9 \\
PEG/50 & $95 / 5$ & 99.6 \\
GLY/20 & $95 / 5$ & 59.3 \\
GLY/50 & $95 / 5$ & 44.0 \\
PEG/20 & $95 / 15$ & 41.5 \\
\hline
\end{tabular}

a Where ethanol and corn-zein concentrations are constant at $95 \%$ and $5 \%$, respectively. 
Table 5

The comparison of oxygen permeability of the conventional coating materials with corn-zein films.

\begin{tabular}{lll}
\hline Film type & $\begin{array}{l}\text { Oxygen transmission } \\
\text { rate }\left(\mathrm{cc} / \mathrm{m}^{2} \times \text { day }\right)\end{array}$ & References \\
\hline Corn-zein & $41.5-99.6$ & From this study \\
Polyvinylidene chloride (PVDC) & 35.8 & Cuq et al. (1998) \\
Ethylene vinyl alcohol (EVOH) & 7.89 & Cuq et al. (1998) \\
Uncoated PP & 2000 & From this study \\
PVDC coated PP & 553 & From Eq. (2) \\
EVOH coated PP & 153 & From Eq. (2) \\
\hline
\end{tabular}

Table 6

The effects of plasticizer type and concentration on contact angles of coated PP films ${ }^{\mathrm{a}}$.

\begin{tabular}{lll}
\hline Plasticizer type & $\begin{array}{l}\text { Plasticizer concentration, \% }(w / w) \\
\text { (based on corn-zein content) }\end{array}$ & Contact angle (degree) \\
\hline PEG & 20 & $51.40 \pm 0.78$ \\
PEG & 50 & $42.40 \pm 2.01$ \\
GLY & 20 & $54.40 \pm 2.67$ \\
GLY & 50 & $50.20 \pm 3.24$ \\
\hline
\end{tabular}

a Where ethanol and corn-zein concentrations are constant at $95 \%$ and $5 \%$, respectively.

\subsection{Contact angles of coated films}

Water contact angles were determined to understand degree of hydrophobic nature of the coated film surface. The degree of hydrophobicity of surface is important for barrier and printable properties of coated films. The contact angle formed between the water droplets placed on the surface of the coated film and the kinetics of spreading is related to the hydrophobicity of the film. It is well known that the water contact angle increases with increasing surface hydrophobicity. The surface hydrophobicity of zein coated films depends on the coating formulation including corn-zein concentration, plasticizer concentration, and plasticizer type. Effects of these parameters examined on the surface hydrophobicity were given in Table 6. According to statistical analysis, solvent, corn and plasticizer concentrations are all important parameters for both PEG and GLY plasticized proteins (Table 7).

Since zein protein contains many non-polar amino acids, and can be considered a hydrophobic protein, it is expected to have high water contact angle reported as in the range of $60^{\circ}$ and $70^{\circ}$ in the literature (Ghanbarzadeh et al., 2006a; Muthuselvi and Dhathathreyan, 2006). In our study, it was found that the addition of plasticizer decreased water contact angle of corn-zein coating. Therefore, the hydrophobicity of the coating layer decreased.

The coating formulated with GLY had higher water contact angle compared to PEG plasticized film. This result was probably due to the strong hydrophilic interaction of PEG with water since PEG

Table 7

Statistical analysis results of contact angle of corn-zein coated PP films.

\begin{tabular}{|c|c|c|c|c|}
\hline \multirow{2}{*}{$\begin{array}{l}\text { WVP } \\
\text { Factors }\end{array}$} & \multicolumn{2}{|l|}{ PEG } & \multicolumn{2}{|l|}{ GLY } \\
\hline & Coeff. SC & $P$ & Coeff. SC & $P$ \\
\hline $\begin{array}{l}\text { Solvent } \\
\quad \text { concentration }\end{array}$ & 7.63513 & $1.0706 \mathrm{e}-005$ & 2.8782 & 6.70192e-008 \\
\hline Corn concentration & -4.8008 & 0.002588 & -5.19997 & $4.6607 e-014$ \\
\hline $\begin{array}{l}\text { Plasticizer } \\
\quad \text { concentration }\end{array}$ & -1.23347 & 0.4083 & 4.33631 & $5.73597 e-012$ \\
\hline $\begin{array}{l}\text { Solvent-corn } \\
\text { interaction }\end{array}$ & -3.80134 & 0.0156465 & 3.68006 & $4.31693 e-010$ \\
\hline $\begin{array}{l}\text { Solvent-plasticizer } \\
\text { interaction }\end{array}$ & -1.24469 & 0.409972 & -0.00747 & 0.98608 \\
\hline $\begin{array}{l}\text { Corn-plasticizer } \\
\text { interaction }\end{array}$ & -5.55989 & 0.000723304 & -1.01932 & 0.021272 \\
\hline
\end{tabular}

Table 8

The effects of ethanol and corn-zein concentration on contact angle of coated PP films ${ }^{\mathrm{a}}$.

\begin{tabular}{lll}
\hline $\begin{array}{l}\text { Ethanol } \\
\text { concentration, \% }\end{array}$ & $\begin{array}{l}\text { Corn-zein concentration } \\
(\mathrm{g} / 100 \mathrm{ml} \text { ethanol) }\end{array}$ & $\begin{array}{l}\text { Contact angle } \\
\text { (degree) }\end{array}$ \\
\hline 70 & 5 & $51.40 \pm 3.37$ \\
70 & 15 & $55.60 \pm 2.01$ \\
95 & 5 & $50.20 \pm 3.24$ \\
95 & 15 & $51.40 \pm 2.01$ \\
\hline
\end{tabular}

a Where plasticizer is glycerol, and its concentration is constant as $20 \%(\mathrm{w} / \mathrm{w})$ based on corn-zein content.

has higher molecular weight and hydrophilic nature than GLY. The increase in amount of plasticizer used in coating resulted in further decrease in water contact angle. The higher hydrophilic nature of coating formed by PEG plasticization was also confirmed by water vapor permeability (WVP) results of coated PP films. The higher WVP was obtained for PP films coated by PEG plasticized corn-zein compared to GLY plasticized films.

Since hydrophobic nature of coating would increase with cornzein concentration, the increase in water contact angle of the coating surface was observed as seen in Table 8. Hydrophobic coating on PP film decreased the surface energy of the coated films, along with decreasing water affinity by increasing the water contact angle.

Similar results were obtained by several researchers (Ghanbarzadeh et al. 2006a,b; Muthuselvi and Dhathathreyan, 2006). Ghanbarzadeh and coworkers determined the effects of plasticizers on hydrophobicity of zein films. The addition of sugar plasticizers to free-standing zein films increased the surface tension of zein films, and resulted in reduction of water contact angle of zein films. However, no significant differences within ethanol and ethylene glycol contact angle of zein films were observed. Similar to our results, the zein films containing GLY had the highest water contact angle compared to other plasticized films (Ghanbarzadeh et al., 2006a). Muthuselvi and Dhathathreyan also found comparable results with this study. They observed significant decrease in contact angle of plasticized zein films compared to films of pure zein (Muthuselvi and Dhathathreyan, 2006).

\section{Conclusions}

In this study, the plasticized corn-zein coatings on polypropylene (PP) films were prepared to investigate the water vapor (WVP) and oxygen (OP) permeability properties of coated films in order to develop a novel film for food packaging applications. These films could provide a higher possibility in recycling processes because of easy separation of coating from the base plastic. The study was aimed at investigating the effects of coating formulation (corn-zein, ethanol, plasticizer concentration and type) on WVP and OP of coated PP films. The final corn-zein coated PP films showed good appearance, flexibility and adhesion between the coating and the base film. The WVP and OP of PP films significantly decreased by corn-zein coating depending on coating formulation. The improvement of water vapor barrier properties of PP coated films was obtained for high concentrations of corn-zein. In addition, the WVP of coated PP films increased with higher amount of polyethylene glycol (PEG) and glycerol (GLY) used as plasticizers because of the increase in free volume between polymer chains. The higher WVP of corn-zein coated PP films observed by plasticization of PEG as compared to GLY due to higher hydrophilicity of PEG. The coating improved OP of PP base film by showing nearly four times lower oxygen permeability than uncoated PP film. The excellent oxygen-barrier for coated PP films was obtained by applying coating solution which consists of higher amount corn- 
zein plasticized with GLY at low level. Therefore, it was observed that the corn-zein coated PP films showed tendency to have high water barrier with proper coating formulations especially high corn-zein content films plasticized with GLY. In conclusion, corn-zein coatings could have potential as an alternative to synthetic coating materials with appropriate formulation.

\section{References}

Bertuzzi, M.A., Vidaurre, C.E.F., Armada, M., Gottifredi, J.C., 2007. Water vapor permeability of edible starch based films. Journal of Food Engineering 80, 972978.

Chandra, R., Rustgi, R., 1998. Biodegradable polymers. Progressive Polymer Science $23,1273-1335$

Cuq, B., Gontard, N., Guilbert, S., 1998. Proteins as agricultural polymers for packaging production. The American Association of Cereal Chemists 75 (1), 1-9.

Cutter, C.N., 2006. Opportunities for bio-based packaging technologies to improve the quality and safety of fresh and further processed muscle foods. Meat Science 74, 131-142.

Debeaufort, F., Quezada-Gallo, J.A., Voilley, A., 1998. Edible films and coatings: tomorrow's packagings: a review. Critical Reviews in Food Science 38 (4), 299313.

Duda, J.L., Vrentas, J.S., Ju, S.T., Liu, H.T., 1982. Prediction of diffusion coefficients for polymer-solvent systems. AICHE Journal 28, 279-285.

Ghanbarzadeh, B., Musavi, M., Oromiehie, A.R., Jomeh, Z.E., Rad, E.R., Milani, J., 2006a. Effect of plasticizing sugars on water vapor permeability, surface energy and microstructure properties of zein films. Food Research International 39 882-890.

Ghanbarzadeh, B., Musavi, M., Oromiehie, A.R., Rezayi, K., Razmi, E., Milani, J., 2006b. Investigation of water vapor permeability, hydrophobicity and morphology of zein films plasticized by polyols. Iranian Polymer Journal 15 (9), 691-700.

Hong, S.I., Krochta, J.M., 2004. Whey protein isolate coating on LDPE film as a novel oxygen barrier in the composite structure. Packaging Technology and Science $17,13-21$.

Hong, S.I., Lee, J.W., Son, S.M., 2005. Properties of polysaccharide-coated polypropylene films as affected by biopolymer and plasticizer types. Packaging Technology and Science 18, 1-9.
Hong, S.I., Krochta, J.M., 2006. Oxygen barrier performance of whey-protein coated plastic films as affected by temperature, relative humidity, base film and protein type. Journal of Food Engineering 77, 739-745.

Hsu, B., Weng, Y., Liao, Y., Chen, W., 2005. Structural investigation of edible zein films/coatings and directly determining their thickness by FT-Raman spectroscopy. Journal of Agricultural and Food Chemistry 53, 5089-5095.

Kumar, A., Gupta, R.K., 1998. Fundamentals of Polymers. McGraw Hill International Editions, Singapore.

Lai, H.M., Padua, G.W., 1997. Properties and microstructure of plasticized zein films. Cereal Chemistry 74 (6), 771-775.

Lawton, J.W., 2004. Plasticizers for zein: their effect on tensile properties and water absorption of zein films. Cereal Chemistry 81 (1), 1-5.

Miller, K.S., Krochta, J.M., 1997. Oxygen and aroma barrier properties of edible films: a review. Trends in Food Science and Technology 8, 228-237.

Muthuselvi, L., Dhathathreyan, A., 2006. Contact angle hysteresis of liquid drops as means to measure adhesive energy of zein on solid substrates. Pramana Journal of Physics 66 (3), 563.

Parris, N., Coffin, D.R., 1997. Composition factors affecting the water vapor permeability and tensile properties of hydrophilic zein films. Journal of Agricultural Food Chemistry 45, 1596-1599.

Rakotonirainy, A.M., Padua, G.W., 2001. Effects of lamination and coating with drying oils on tensile and barrier properties of zein films. Journal of Agricultural Food Chemistry 43, 2860-2863.

Reddy, C.S.K., Ghai, R., Rashmi, V.C., 2003. Polyhydroxyalkanoates: an overview. Bioresource Technology 87, 137-146.

Shin, G.H., Lee, Y.H., Lee, J.S., Kim, Y.S., Choi, W.S., Park, H.J., 2002. Preparation of plastic and biopolymer multilayer films by plasma source ion implantation. Journal of Agricultural Food Chemistry 50, 4608-4615.

Shukla, R., Cheryan, M., 2001. Zein: the industrial protein from corn. Industrial Crops and Products 13, 171-192.

Tharanathan, R.N., 2003. Biodegradable films and composite coatings: past, present and future. Trends in Food Science and Technology 14, 71-78.

US Congress, Office of Technology Assessment, 1993. Biopolymers: Making Materials Nature's Way-Background Paper, OTA-BP-E-102. US Government Printing Office, Washington, DC. pp. 25-48.

Wang, Y., Padua, G.W., 2006. Water barrier properties of zein-oleic acid films. Cereal Chemistry 83 (4), 331-334. 